\title{
Cinema em sala de aula: reflexões a respeito do emprego de filmes na prática docente'
}

\author{
Humberto Perinelli Neto \\ Universidade Estadual Paulista \\ Rodrigo Ribeiro Paziani \\ Universidade Estadual do Oeste do Paraná
}

\section{Resumo}

Atualmente, várias são as reflexões sobre o diálogo entre Tecnologias da Informação e Comunicação e Educação. Este artigo, visa, pois, apresentar pesquisa, procurando traçar entendimento sobre o emprego de cinema em salas de aulas do Ensino Fundamental I. Por meio de método "qualiquantitativo", traçam-se os limites e as possibilidades vinculadas à utilização escolar desse tipo de linguagem. Busca-se, assim, colaborar com a apropriação do cinema nos processos formativos educacionais baseados na autonomia pedagógica, na construção do aprendizado crítico e lúdico e na validade de propostas de ensino, caracterizadas pela inter e transdisciplinaridade. Palavras-chave: Prática docente. Tecnologias. Cinema e educação.

\section{Cinema in the classroom: reflections on the film employment in tea- ching practice}

\section{Abstract}

Currently, there are several reflections on the dialogue between the Information and Communication Technologies and Education. This article therefore aims to present research, seeking to draw understanding of the use of film in elementary school classrooms I. Through method "quantitative and qualitative", are traced the limits and possibilities linked to school use of this kind of language. We search, therefore, to collaborate with the appropriation of film in educational training processes based on pedagogical autonomy in the construction of critical and playful learning and validity of proposals characterized by inter and transdisciplinary.

Keywords: Teaching practice. Technologies. Cinema and education. 


\section{Cine en el aula: reflexiones sobre el uso de películas en la práctica docente}

\section{Resumen}

Actualmente, hay varias reflexiones sobre el diálogo entre las Tecnologías de la Información y la Comunicación y Educación. Por lo tanto, este artículo tiene como objetivo presentar la investigación, tratando de llamar la comprensión del uso del cine en las aulas de la escuela primaria I. A través de método "cuantitativo y cualitativo", se remontan los límites y posibilidades vinculadas a uso de la escuela de ese tipo de lenguaje. El objetivo es cooperar así con la apropiación de la película en los procesos de formación educativos basados en la autonomía pedagógica en la construcción del aprendizaje crítico y lúdico y la validez de las propuestas de enseñanza que se caracterizan por inter y transdisciplinariedad.

Palabras clave: Practica docente. Tecnologías. El cine y la educación.

\section{Cinema e educação}

As interfaces entre cinema e educação não representam novidade, uma vez que reflexões e usos de filmes (e de outras linguagens audiovisuais) em projetos e atividades educativas escolares ou extra escolares têm sido analisadas por gama variada de autores (SOARES, 1994; CARVALHO, 1998; KONRATH; CARNEIRO; CARVALHO; TAROUCO, 2006; ARAÚJO FILHO, 2007; DUARTE; LEITE; MIGLIORA, 2004; DUARTE, 2009; FONSECA, 2009).

Para Duarte (2009), por exemplo, o cinema imprime marcas tão profundas nas maneiras de ser e de existir das pessoas, que os filmes acabam por fazer parte de um "processo civilizatório", de modo que os professores devem conhecer a história e a linguagem do cinema para usá-lo de forma consciente e qualitativa em suas práticas educativas.

Falando sobre cinema e ensino de História, Nascimento (2008, p. 14) afirma que a utilização do cinema para a "ilustração" de um determinado tema histórico, por exemplo, "[...] pode enriquecer o aprendizado e facilitar a compreensão do tema a ser trabalhado".

Pontuska, Paganelli e Cacete (2009, p. 59) valorizam a relação cinema e escola, destacando que a última "[...] cumpre papel importante ao 
apropriar-se das várias modalidades de linguagens como instrumentos de comunicação $[\ldots]$ ", visto que oportuniza o desenvolvimento da "[...] capacidade do aluno de assimilar as mudanças tecnológicas que, entre outros aspectos, implicam também novas formas de apreender".

De fato, responsáveis por enorme revolução cultural no século XX, os filmes passaram a reunir, em si mesmos as outras artes (dança, teatro, música, literatura, pintura e escultura) e, cada vez mais, deixaram de ser meros "registros do movimento" (ARAÚJO, 1995; BENTES, 2007).

Pode-se dizer, verdadeiramente, que os filmes expressam a capacidade de transformar o mundo em discurso (CHARNEY; SCHWARTZ, 2001), segundo um particular sistema simbólico de produção/reprodução de significados, daí expressões como cultura e linguagem cinematográficas.

A importância alcançada pelas narrativas cinematográficas guarda vínculo com a gradativa transformação do olhar e da sensibilidade humana, processada ao longo do que se denomina por modernidade (CRARY, 1995; NOVAES, 1997; ALMEIDA, 2009).

Entre os séculos XVII e XVIII, o observador tendia a ser isolado, imóvel, já que apenas espreitava o mundo exterior, por meio da câmara escura.

Com a invenção da fotografia no século XIX, em especial, foi criado um "[...] sistema irredutivelmente heterogêneo de relações discursivas, sociais, tecnológicas e institucionais [...]" (CRARY, 1995, p. 6-7), que operou com a decodificação e com a desterritorialização da visão, efeitos que guardam relação com a indústria da imagem e do espetáculo organizadas, especialmente, no século XX.

Atualmente, é possível notar o estímulo ao emprego de cinema nos processos formativos, mas de forma a se evitar o tecnicismo e a reificação em torno dessa linguagem, preocupações que, de modo geral, impelem a novas reflexões, visando fugir de certa tradição do emprego de filmes no campo da educação, registrada no Brasil (CATELI, 2007; MONTEIRO, 2006; SALIBA, 20031.

Com base em estudiosos que buscam compreender de modo critico a relação entre mídia e educação (SETTON, 2004; DUARTE, 2009; BELLONI; BÉVORT, 2009; FISCHER, 2009; COLL; MONEREO, 20101, defende-se o entendimento dos filmes enquanto discursos carregados de intencionalidade/ ideologia, ao mesmo tempo que se argumenta a favor da validade de tratá-los 
como sendo objetos de estudo e como instrumentos pedagógicos interessantes no âmbito das práticas escolares, na companhia de outras Tecnologias de Informação e Comunicação.

Devido à defesa do cinema na construção de práticas pedagógicas, vivenciam-se experiências envolvendo a produção de materiais audiovisuais no ambiente escolar, se valendo, assim, da mudança na relação estabelecida com as imagens fílmicas nas últimas décadas, isto é, da expansão da proposta de "documentação filmográfica do real" (MESQUITA; LINS, 2008; MOLETTA, 2009) e da acessibilidade a câmeras filmográficas (DE LUCA, 2009) e softwares gratuitos de edição pela internet (VARGAS; ROCHA; FREIRE, 2007).

Várias iniciativas têm resultado dessas experiências.

Primeiramente, o desenvolvimento de curso de extensão por um grupo de docentes e técnicos, especialmente voltado para oferecer saberes a respeito do cinema e incentivar a apropriação dessa linguagem pelos atores envolvidos com ações educativas.

Soma-se a isso, a organização de Mostra anual de curtas metragens, visando divulgar tais vídeos, assim como estender a um público maior o aprendizado constituído por ocasião da elaboração desses materiais e a riqueza pedagógica que encerram.

Por fim, registra-se, ainda, a criação do site "Cin/educ/ação", dedicado a abrigar vários curtas metragens, produzidos por professores em formação, bem como outras ferramentas (textos, resenhas fílmicas, experiências pedagógicas, ferramentas técnicas, etc.).

Todas essas iniciativas impeliam o grupo envolvido a desenvolver projeto de formação continuada junto à rede municipal de ensino de São José do Rio Preto, dedicado a incentivar a construção de práticas pedagógicas com base no emprego do cinema.

Foi, exatamente nesse momento, que se passou a considerar fundamental o desenvolvimento de "pesquisa de base", que permitisse traçar certo panorama da presença da linguagem cinematográfica nas ações apresentadas pelos docentes que atuam em tal sistema de ensino, por acreditar que tal entendimento antecedia qualquer outra ação pretendida junto a esses profissionais.

$\bigcirc$ presente artigo apresenta, justamente, reflexões construídas a partir dessa preocupação, tendo em vista a investigação associada à pesquisa 
"Educação e tecnologias: estudo do emprego da linguagem cinematográfica no Ensino Fundamental $1\left(7^{\circ}\right.$ a $5^{\circ}$ anos) da rede municipal de ensino de São José do Rio Preto (SP)", desenvolvida entre 2013 e 2014 , por meio do "Renove" - Programa da Pró-Reitoria de Pesquisa da Unesp, cujo objetivo é apoiar o desenvolvimento de projetos de pesquisa.

\section{Delineamento de uma pesquisa}

presente trabalho é de natureza descritiva, explicativa e abordagem "qualiquantitativa" (MINAYO; DESLANDES; GOMES, 2000; TRIVINÕS, 1992; GAMBOA, 1997), tendo sido aplicados questionários em unidades escolares representativas (ANDRÉ; LUDKE, 2005), com apoio no Método de Survey (BABBIE, 2005) e interpretação dos dados, com base em referências que tratam de "cinema e educação", "linguagem cinematográfica" e "formação docente".

Visamos descrever características de certa população ldocentes que atuam no Ensino Fundamental I da rede pública municipal de São José do Rio Preto, SP), por meio da definição de uma categoria de análise (emprego de fit-

182 mes na prática docente) e o uso de técnicas padronizadas de coleta de dados (questionários majoritariamente fechados).

Para tanto, foram entrevistados oitenta e sete docentes que atuam em cinco escolas distintas de São José do Rio Preto (Quadro 1), tendo em vista as diferenças socioespaciais presentes na composição urbana (AZEVEDO, 2004; CARVALHO, 2007) e particularidades que caracterizaram o processo de municipalização do ensino nessa cidade (FARIA, 2008). 


\section{Quadro 1}

\section{Escolas da rede municipal de São José do Rio Preto (SP) pesquisadas}

\begin{tabular}{|l|c|c|c|c|c|}
\hline \multicolumn{1}{|c|}{ Escolas } & $\begin{array}{c}\text { Á } r \text { e a } \\
\text { urbana }\end{array}$ & Docentes & Coordenadores & $\begin{array}{c}\text { Diretores e } \\
\text { Assistentes }\end{array}$ & Discentes \\
\hline E. M. "Prof. Riscieri Berto" & Norte & 22 & 1 & 1 & 560 \\
\hline $\begin{array}{l}\text { E. M. "Prof. Michel Pedro } \\
\text { Sawaya" }\end{array}$ & Sul & 33 & 1 & 1 & 687 \\
\hline E. M. "Prof. Oldemar Stobbe" & Oeste & 10 & 1 & 1 & 419 \\
\hline E. M. "Profa . Guiomar Maia" & Leste & 11 & 1 & 1 & 280 \\
\hline Prof. "Prof. Oscar Arantes Pires" & Centro & 11 & 1 & 1 & 288 \\
\hline 5 & - & 87 & 5 & 5 & 2234 \\
\hline
\end{tabular}

Fonte | Informações obtidas diretamente nas secretárias das próprias escolas pesquisadas

Os dados obtidos, nas entrevistas, foram tabulados com auxílio de software (SPSS, 2011 ) e apresentados sob forma de porcentagens, expressas no Quadro 2.

Quadro 2

Tabulação das respostas do "Questionário Docente"

\begin{tabular}{|c|c|c|c|c|c|c|c|c|}
\hline \multirow{14}{*}{ 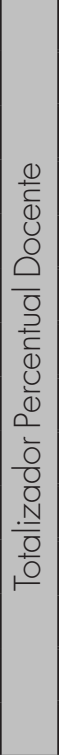 } & Alternativas & $A$ & $B$ & C & $a e b$ & $b e c$ & $a \in c$ & $a, b \in c$ \\
\hline & Questão n ${ }^{\circ} 1$ & $24,5 \%$ & $55,9 \%$ & - & $19,6 \%$ & - & - & - \\
\hline & Questão n 2 & $98,4 \%$ & $1,6 \%$ & - & - & - & - & - \\
\hline & Questão n 3 & - & $42,6 \%$ & $57,4 \%$ & - & - & - & - \\
\hline & Questão n ${ }^{\circ} 4$ & $72,1 \%$ & $16,4 \%$ & $11,5 \%$ & - & - & - & - \\
\hline & Questão n ${ }^{\circ} 5$ & \multicolumn{7}{|c|}{ Diversos (verificar QUADRO 3) } \\
\hline & Questão $n^{\circ} 6$ & $39,3 \%$ & $34,4 \%$ & $24,7 \%$ & - & $1,6 \%$ & - & - \\
\hline & Questão n 7 & $36,1 \%$ & $36,1 \%$ & $27,8 \%$ & - & - & - & - \\
\hline & Questão no 8 & $42,5 \%$ & $45 \%$ & $12,5 \%$ & - & - & - & - \\
\hline & Questão n ${ }^{\circ} 9$ & $47,5 \%$ & $18,1 \%$ & $34,4 \%$ & - & - & - & - \\
\hline & Questão n ${ }^{\circ} 10$ & $62,3 \%$ & $26,2 \%$ & $11,5 \%$ & - & - & - & - \\
\hline & Questão n ${ }^{\circ} 11$ & $72,1 \%$ & - & $27,9 \%$ & - & - & - & - \\
\hline & Questão n 12 & $16,4 \%$ & $8,2 \%$ & $41 \%$ & $9,8 \%$ & $6,5 \%$ & $4,9 \%$ & $13,2 \%$ \\
\hline & Questão n 13 & $57,5 \%$ & $14,7 \%$ & $4,9 \%$ & $6,5 \%$ & $1,6 \%$ & $1,6 \%$ & $13,2 \%$ \\
\hline
\end{tabular}


Cinema em sala de aula: reflexões a respeito do emprego de filmes na prática docente

\begin{tabular}{|c|c|c|c|c|c|c|c|c|}
\hline \multirow{18}{*}{ 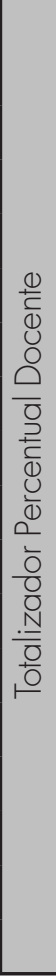 } & Alternativas & $A$ & $B$ & C & $a \in b$ & $b e c$ & $a \in c$ & $a, b \in c$ \\
\hline & Questão n ${ }^{\circ} 14$ & $11,5 \%$ & $77 \%$ & $11,5 \%$ & - & - & - & - \\
\hline & Questão no 15 & $68,8 \%$ & $14,8 \%$ & $3,3 \%$ & $4,9 \%$ & $4,9 \%$ & - & $3,3 \%$ \\
\hline & Questão n 16 & $41 \%$ & $31,1 \%$ & $27,9 \%$ & - & - & - & - \\
\hline & Questão n 17 & $31,1 \%$ & $57,4 \%$ & $1,6 \%$ & $9,9 \%$ & - & - & - \\
\hline & Questão n 18 & $67,2 \%$ & $13,1 \%$ & $3,3 \%$ & $16,4 \%$ & - & - & - \\
\hline & Questão n 19 & $27,9 \%$ & $24,7 \%$ & $13,1 \%$ & $31,1 \%$ & - & $1,6 \%$ & $1,6 \%$ \\
\hline & Questão n ${ }^{\circ} 20$ & $44,2 \%$ & $27,9 \%$ & $9,9 \%$ & $13,1 \%$ & $1,6 \%$ & - & $3,3 \%$ \\
\hline & Questão n ${ }^{\circ} 21$ & $34,6 \%$ & $49,1 \%$ & $6,5 \%$ & $1,6 \%$ & - & $3,3 \%$ & $4,9 \%$ \\
\hline & Questão n 22 & $34,6 \%$ & $37,7 \%$ & $1,6 \%$ & $19,6 \%$ & - & $1,6 \%$ & $4,9 \%$ \\
\hline & Questão n 23 & $50,8 \%$ & $11,5 \%$ & $14,8 \%$ & $18 \%$ & - & $4,9 \%$ & - \\
\hline & Questão n 24 & $4,9 \%$ & $77,1 \%$ & $4,9 \%$ & $11,5 \%$ & $1,6 \%$ & - & - \\
\hline & Questão n 25 & $22,9 \%$ & $37,8 \%$ & $34,4 \%$ & $4,9 \%$ & - & - & - \\
\hline & Questão n 26 & $52,5 \%$ & $27,9 \%$ & $19,6 \%$ & - & - & - & - \\
\hline & Questão n ${ }^{\circ} 27$ & $41 \%$ & $41 \%$ & $18 \%$ & - & - & - & - \\
\hline & Questão n 28 & $6,5 \%$ & $88,6 \%$ & $4,9 \%$ & - & - & - & - \\
\hline & Questão n ${ }^{\circ} 29$ & $4,9 \%$ & $90,2 \%$ & $4,9 \%$ & - & - & - & - \\
\hline & Questão n 30 & & & & & & & \\
\hline
\end{tabular}

Nota | 35 das 87 docentes pesquisadas cursaram Magistério, isto é, 40,23\%

Com base nas porcentagens, foram construídas interpretações, visando estabelecer compreensão das situações investigadas em torno do tema em questão, o que permitiu somar métodos e procedimentos qualitativos à pesquisa (ALVES-MAZZOTTI; GEWANDSZNAJDER, 1999; DENZIN; LINCOLN, 2006).

Os questionários possuíam a seguinte configuração: 30 perguntas, das quais 28 eram fechadas e apresentavam três alternativas, enquanto as outras duas eram abertas. Além disso, os questionários eram compostos por "Apresentação da pesquisa" e conjunto de "Informações" (perguntas que visavam traçar um perfil do docente).

Outros dois pontos sobre tais questionários merecem ainda destaque. Primeiro: foram aplicados nas próprias escolas onde os docentes atuam e seu preenchimento foi efetuado de forma individual e por escrito. Segundo: não se previa controle de variáveis como sexo e nível socioeconômico, uma vez que 
foram preservadas as características do meio real (unidades escolares) onde foram aplicados.

A exposição das interpretações levou em conta o agrupamento das respostas segundo os três eixos constituintes do questionário aplicado: "cotidiano, formação docente e cinema", "práticas educativas e cinema" e "formação continuada e cinema".

\section{Cotidiano, formação docente e cinema}

A questão 1 envolvia a definição de cinema e, entre as opções existentes (arte, linguagem e outra), a maioria (55.9\%) afirmou que se trata de arte, o que pode sugerir um entendimento, apenas, contemplativo, baseado numa apreciação estética passional.

Ismail Xavier (2002, p. 369-370) aborda essa "apreciação estética", ao enfatizar que o cinema envolve: a) o processo de filmagem, com todos os riscos, compromissos e olhares daquele(s) que têm o poder de escolher 'o quê'e 'como' filmar, e b) o consumo do filme, representado pela figura do espectador que "assiste" à película, sem obter o privilégio da escolha, muitas vezes, inclusive, deixando de reconhecer que ela existe.

As respostas à questão 2 indicam que a quase totalidade dos docentes $(98,4 \%)$ aprecia o cinema. O que isso significa?

De certa forma, representa o poder que o cinema (ou o audiovisual) exerce na elaboração de imaginários sociais, na medida em que "[...] cria certos símbolos capazes de influenciar na constituição de códigos de sociabilidade" (PERINELLI NETO, 201 1, p. 120).

Ademais, tal resposta registra a penetração das linguagens audiovisuais no cotidiano das pessoas, a ponto de se ler e ouvir referências à expansão de uma inexorável (e perigosa) sociedade consumidora de imagens, cujo alcance - inclusive pedagógico - ainda é difícil de dimensionar e avaliar (BITTENCOURT, 2011 ; JOLY, 2012).

As questões 3, 4 e 5 guardam em comum a preocupação em entender a presença do cinema no cotidiano dos docentes. 
Cinema em sala de aula: reflexões a respeito do emprego de filmes na prática docente

Observa-se, nas respostas à questão 3, que a maioria, raramente, frequenta o cinema $(57,4 \%)$, embora porcentagem também expressiva o faz mensalmente $(42,6 \%)$.

Tais dados fazem pensar na proposição de estratégias, necessárias para aproximar o docente do cinema. Isto porque, como enfatiza Rosália Duarte:

Defendemos o direito de acesso amplo e universal ao conhecimento, mas não defendemos o direito de acesso ao cinema - o Brasil é um dos países em que o ingresso no cinema está entre os mais caros do mundo. Até quando ignoraremos o fato de que cinema é conhecimento? (DUARTE, 2009, p. 18-19, grifo nosso).

Na respostas à questão 4, a maioria esmagadora $(71,8 \%)$ destacou que assiste, semanalmente, a filmes exibidos na televisão.

$\bigcirc$ acesso aos filmes por esse meio pode representar situação favorável ao emprego de filmes em sala, mas exige, de qualquer modo, que um trabalho formativo, envolvendo a apropriação pedagógica do audiovisual, seja promovido, o que significa proporcionar aos docentes conhecimentos 186 sobre a linguagem e a cultura cinematográficas (DUARTE, 2009) e, a contar daí, sobre as relações entre ética e estética (FISCHER, 2009), cinema e memória (ALMEIDA, 2009), entre outros.

É necessário incluir, neste trabalho formativo, reflexões a respeito do uso de cinema em situações de aprendizagem (NAPOLITANO, 201 1), o que implica o professor entender - além da "estrutura comunicativa e estética de um filme" - o conhecimento que os sujeitos, envolvidos na experiência audiovisual, possuem de cinema, bem como as condições técnicas oferecidas pela escola.

Conhecendo sobre a linguagem e a cultura cinematográficas, assim como o uso de cinema em situações de aprendizagem, poderão os docentes desenvolver a apropriação pedagógica de filmes de modo autônomo, crítico e criativo, especialmente se o processo formativo proposto também envolver (e de modo especial) a valorização dos "saberes para a prática docente" (FREIRE, 2008), os "saberes docentes" (TARDIF, 2002) e os "saberes pedagógicos" (PIMENTA, 1999).

Vale registrar, ainda, que as respostas à questão 5 permitem identificar a diversidade de gêneros fílmicos assistidos pelos docentes nos canais 
televisivos (Quadro 3), sendo os mais indicados, pela ordem, aqueles denominados por "romance", "comédia", "drama", "suspense", "ação", "documentário", "aventura", "comédia romântica" e "infantil".

\section{Quadro 3}

Gêneros de filmes apresentados na TV e assistidos pelos docentes

\begin{tabular}{|c|c|c|c|c|c|c|}
\hline Ação & Auto Ajuda & Arte & Aventura & Científico & Comédia & $\begin{array}{c}\text { Comédia } \\
\text { Romântica }\end{array}$ \\
\hline $19,7 \%$ & $1,4 \%$ & $4,2 \%$ & $16,9 \%$ & $5,6 \%$ & $40,8 \%$ & $16,9 \%$ \\
\hline Curta & & & & & & \\
\hline Metragem & Documentário & Drama & Épico & Existencial & Ficção & Infantil \\
\hline $2,8 \%$ & $19,6 \%$ & $27,9 \%$ & $9,8 \%$ & $6,5 \%$ & $14,8 \%$ & $16,4 \%$ \\
\hline Interessante & Pedagógico & Policial & Religioso & Romance & Suspense & Terror \\
\hline $1,6 \%$ & $6,5 \%$ & $8,2 \%$ & $3,3 \%$ & $47,5 \%$ & $21,3 \%$ & $6,5 \%$ \\
\hline
\end{tabular}

Nota | Os próprios docentes pesquisados indicaram os gêneros mencionados

Ao contrário do que muitos supõem, o bom aproveitamento de filmes em ambientes escolares não envolve, apenas, títulos de "documentários" ou qualquer outra obra tida por "pedagógica". A apropriação fílmica para fins educativos exige, na verdade, uma sistematização didática que ganha força quando se apoia em produções conhecidas, dado o fato de, possivelmente, se comunicarem mais facilmente com os discentes (NAPOLITANO, 2011; FONSECA, 20091.

Nesse sentido, pode-se afirmar que não existe, a priori, filme mais adequado para atividades em sala de aula, mas sim, aquele que é mais bem pensado para o desenvolvimento do trabalho pedagógico; daí a necessidade de se reconhecer a significância da preparação promovida pelo docente e, portanto, os predicados de sua formação no sentido mais amplo /conceito que possui sobre educação, papel social da escola, missão do professor, relação entre professor e aluno, entre outros).

Exemplos claros disso podem ser encontrados nos trabalhos elaborados no campo da filosofia por Julio Cabrera e Ollivier Pourrioul. Cabrera (2006) propõe discutir conceitos-chave de vários filósofos ocidentais (De Platão a Wittingenstein), por meio da exibição e debate de filmes como " $\bigcirc$ franco 
atirador", "Batman I e II", "Os imperdoáveis" e filmes mudos, como os de Chaplin. Já Ollivier Pourriol (2009) propõe o entendimento de filósofos ocidentais modernos (Descartes, Spinoza, Leibniz, entre outros), valendo-se de títulos cinematográficos como "Clube da Luta", "Efeito Colateral" e "Sexto Sentido".

Quando se analisam as questões 6, 7, 8, 9 e 10, constata-se que todas buscavam traçar as experiências envolvendo cinema e educação, ocorridas durante a formação escolar e inicial dos docentes pesquisados.

Em relação ao Ensino Fundamental, segundo respostas obtidas na questão 6 , nota-se que 39,3\% atestaram uso de filmes nas aulas; 34,4\% afirmaram não haver vivenciado experiências dessa natureza, enquanto 24,7\% indicaram que ocorreu raramente.

No que tange ao Ensino Médio, os números extraídos, na questão 7 , são muito parecidos aos registrados no Ensino Fundamental: 36, 1 \% afirmaram que houve emprego de filmes e outros 36, 1 \% que não, com pequeno aumento do índice $(27,8 \%)$ daqueles que afirmaram ter sido rara a experiência envolvendo cinema e educação.

A pouca presença dos filmes ou o emprego superficial dessa linguagem durante o processo de escolarização básica é fator que, provavelmente, interfere na opção que os docentes farão dessa linguagem em suas práticas pedagógicas, devido ao peso que experiências desse tipo exercem na formação do futuro professor (TARDIF, 2002).

Já na questão 8, dedicada à formação recebida durante o Magistério, a opinião foi bem dividida, já que $42,5 \%$ indicaram a existência do diálogo entre cinema e educação, enquanto $45 \%$ a negaram.

Constatou-se, na questão 9, que o uso do cinema durante a formação inicial (graduação) foi maior, seja porque os filmes foram versados com mais frequência $(47,5 \%)$ ou raramente $(34,4 \%)$.

Por fim, segundo a opinião dos próprios docentes, expressa nas respostas à questão 10, a experiência foi, em geral, positiva, já que: $62,3 \%$ a consideraram satisfatória; 26,2\% insatisfatória; e 11,5\% a qualificaram como sendo razoável.

Oaumento já indicado da frequência do emprego de filmes durante a vivência do Magistério e/ou da Graduação pode explicar a opinião positiva, já que a exibição e o debate dos títulos podem ter salientado o potencial diálogo entre cinema e educação. 
Contudo, as respostas atribuídas às questões 8,9 e 10 suscitam dúvidas quanto ao avanço na compreensão do filme como expressão artística dotada de linguagem e cultura próprias, devido, especialmente, às opções assinaladas pelos docentes no tópico "práticas educativas e cinema" lquestões 11 a 291, isto é, na parte da pesquisa que permite, exatamente, apresentar as apropriações pedagógicas, promovidas por eles em sala de aula.

\section{Práticas educativas e cinema}

As questões 11, 12, 13 e 14 visaram traçar o entendimento da utilização do cinema nas práticas educativas, desenvolvidas pelos docentes pesquisados.

Assim, a maioria afirmou, na questão 11, que emprega vídeos em suas aulas, seja de modo frequente $(72,1 \%)$ ou raramente $(27,9 \%)$, sendo o filme considerado "pedagógico" (isto é, adequado para uso em sala de aula) o mais citado (41\%), conforme respostas à questão 12.

Investigadas as influências que operam sobre o uso de filmes nas práticas educativas, constatou-se, nas respostas atribuídas à questão 13, que $57,5 \%$ dos docentes lançam mão desse material por conta própria e que a grande maioria (77\%) é motivada pelos conteúdos dos filmes, segundo as respostas registradas na questão 14 .

Nesse sentido, pode-se deduzir que a presença do cinema na educação promovida pelos docentes não é acompanhada de um tratamento sistemático e planejado do ponto de vista coletivo.

Por que será que isso ocorre?

Será que é decorrente das iniciativas predominantemente individuais dos próprios docentes, de ações difusas da gestão didático-pedagógica da unidade escolar ou da política educacional adotada pelas redes de ensino? Qualquer uma dessas opções ou a articulação delas poderia resultar em respostas plausíveis (e não sem alguma razão). Mas, talvez, não deem conta da "questão-chave" que permeia tal problema.

De acordo com Barreto (2002), a partir de meados da década de 1990, organismos internacionais (como o Banco Mundial e a Comissão Econômica para a América Latina e o Caribe - Cepall passaram a defender 
e sustentar a tese de que era necessária a "[...] incorporação educacional das tecnologias da informação e da comunicação" (BARRETO, 2002, p. 89). Associada diretamente à redução do papel do Estado no financiamento da educação, bem como à diminuição de custos de ensino, a tese envolvia a aquisição de "kits tecnológicos" (também chamados de "pacotes instrucionais") nas escolas públicas e no treinamento dos professores.

No Brasil, essas mudanças são perceptíveis desde a década de 1970, quando da opção dos governos militares pela valorização do tecnicismo pedagógico (FONSECA, 1993). Porém, elas foram aprofundadas a contar de 1995, com a criação pelo MEC da Secretaria de Educação a Distância (SEED) e um conjunto de programas do governo federal, voltados à utilização de tecnologias em situações de aprendizagem (TV Escola, Prolnfo, PAPED etc.).

Contudo, onde estaria a "questão-chave" do problema apontado nas questões 13 e 14 ? De acordo com Raquel Goulart Barreto:

Se o discurso dos organismos internacionais promove o centramento das tecnologias da informação e da comunicação, o MEC vai além, operando um deslocamento sintático radical: a colocação de um sistema tecnológico na posição de sujeito [...] Por outro lado, como as características mais destacadas deste indefinido sistema tecnológico são o preço, a acessibilidade e a simplicidade de manuseio, sua inscrição sugere não apenas que as tecnologias sejam capazes de operar uma 'revolução educacional', mas que o trabalho com elas seja simples, esteja pronto e venha embalado em um pacote ou kit fácil de desembrulhar (BARRETO, 2002, p. 93-94, grifo nosso).

$\bigcirc$ que se pode depreender dessa afirmativa, especialmente quando articulada ao problema da carência de um emprego sistematizado e planejado do cinema em práticas pedagógicas escolares pensadas coletivamente?

Entende-se que a "questão-chave" não é o voluntarismo docente, tampouco a falta de ação da gestão da unidade escolar, nem, ainda, a postura assumida pela rede de ensino, mas, fundamentalmente, o descaso dos governos (estadual, federal) em desconsiderar uma formação integral dos professores e não reconhecer, inclusive, a relevância da linguagem audiovisual (caso do cinema) no próprio processo formativo do "ser", do "fazer" e do "refletir" docente (FREIRE, 2008). 
Voltando ao questionário, as questões 15, 16 e 17 objetivavam traçar o entendimento dos aspectos técnicos e arquitetônicos envolvendo o emprego educativo de filmes desenvolvidos pelos docentes.

Acerca dos aspectos técnicos, a maioria $(68,8 \%)$ indicou, na questão 15, que televisão e aparelhos de DVD ou VHS são os equipamentos utilizados com mais frequência para exibição de vídeos em aula.

É difuso o motivo de utilizar mais correntemente os equipamentos citados, como sugerem as respostas à questão 16: $41 \%$ afirmaram que permitem melhor qualidade, 31, 1\% indicaram ser os únicos que a escola oferece e $27,9 \%$ declararam se tratar daqueles que sabiam manusear.

Quanto aos aspectos arquitetônicos, de acordo com os entrevistados na questão 17, o espaço da unidade escolar normalmente utilizado para exibição de filmes é a sala de vídeo ou similar $(57,4 \%)$, embora a sala de aula tenha sido significativamente citada (por cerca de 1/3 dos professores $-31,1 \%$.

Entende-se que experiências associadas à formação continuada poderiam fazer com que o emprego do cinema na educação não estivesse vinculado, apenas, à aquisição de equipamentos técnicos e a readequação dos espaços físicos das escolas para exibição de filmes, mas também no reconhecimento, por parte da gestão, especialmente, da pertinência pedagógica da produção filmográfica (daí a necessária aquisição de câmeras e softwares de edição, por exemplo) pelos próprios docentes e discentes (PERINELLI NETO, 2011 ; ALMEIDA; VALENTE, 20121.

Na sequência, foram alvo de reflexões as respostas atribuídas às questões 18, 19 e 20, dedicadas ao entendimento do contexto, envolvendo o emprego de filmes nas práticas educativas.

Na questão 18, nota-se que a maioria $(67,2 \%)$ afirmou que os filmes são obtidos por conta própria (videolocadoras, internet, gravando da TV), parcela menor $(16,4 \%)$ indicou que são por conta própria ou na escola e na Secretaria de Educação, enquanto um número tímido $(13,1 \%)$ atribuiu tal obtenção, apenas, à escola ou à Secretaria de Educação.

Segundo os docentes, igualmente difusa é a circunstância envolvendo o emprego do filme em práticas educativas, conforme registrado na questão 19: 27,9\% afirmaram que ocorre no Início da abordagem de um tema/ assunto; $24,7 \%$ sinalizaram que se dá no encerramento da abordagem de um 
tema/assunto; 13, 1\% mencionaram outra maneira e 31, 1\% pontuaram que se processa no início e no encerramento da abordagem de um tema/assunto.

Não existe consenso sobre o melhor momento de abordagem do filme, mas é fato que é necessário "planejamento pedagógico", levando-se em conta, para isso, a duração do vídeo e a faixa etária escolar contemplada, para que seja evitado o "efeito de super-representação fílmica", isto é, experiência audiovisual que "pode induzir a uma assimilação direta, sem mediações, da representação fílmica", gerando a confusão entre o "real" e o "simulacro" (NAPOLITANO, 201 1, p. 39).

Na questão 20, foi perguntado qual é o conjunto de disciplinas em que os docentes mais se valem de filmes, destacando-se "História, Geografia e Ciências" (44,2\%), embora também seja expressivo o índice associado à "Língua Portuguesa e Matemática" (27,9\%), especialmente, quando se considera que 13,1\% assinalaram uso de filmes nos dois conjuntos citados e que, apenas, 9,9\% mencionaram "Artes e Educação Física".

As questões 21 , 22 e 23 permitem compreender alguns procedimentos relacionados ao emprego dos filmes.

No que tange à questão 21 , a maioria dos docentes (49,1\%) afirmou que opta por filmes com mais de uma hora de duração, apresentando-os integralmente em sala de aula; entretanto, 34,6\% indicaram que optam por filmes curtos, com duração inferior a uma hora.

A opção por apresentar filmes com mais de uma hora de duração, portanto, provavelmente na integralidade, pode sugerir, em alguns casos, a utilização menos assertiva e planejada de vídeos em sala de aula, daí tal prática ser, muitas vezes, associada a "matar o tempo", além dos riscos sempre presentes de se cair nas armadilhas do "vídeo-deslumbramento" ou do "só vídeo" (MORAN apud NAPOLITANO, 2011 ).

Já a questão 22 permite entender que muitas são as opiniões sobre o momento em que devem ser tecidos comentários a respeito do filme empregado nas práticas educativas: $34,6 \%$, antes de exibi-lo; $37,7 \%$, depois de exibi-lo; e 19,6\% nas duas ocasiões mencionadas.

$\bigcirc$ fato de a opção por filmes se dever a escolhas dos próprios docentes pode resultar no desenvolvimento de práticas educativas cuja abordagem dos filmes ocorre em momentos distintos, como sugerem as respostas à questão 22. Essa diversidade pode representar experiências ricas no emprego 
dessa linguagem, desde que, igualmente, partam da necessária substituição do "mero espectador" pela formação de um sujeito capaz de tecer análises críticas e de constituir sensibilidade para apreciar os elementos estéticos de um filme (FISCHER, 2009).

Do conjunto de docentes ouvido na questão 23 , registra-se que o emprego de filmes é acompanhado, na maioria das oportunidades, por "avaliação baseada em debates" (50,8\%) ou por avaliações constituídas por "debates acrescidos da elaboração de redação, relatório ou outro tipo de avaliação baseada na escrita" (1 8\%).

Embora as propostas de debate de filmes para aprofundar conteúdos trabalhados junto aos alunos não possam ser de todo desabonadas, as respostas à questão 23 aludem a necessidade de ter em mente que a linguagem cinematográfica (e/ou audiovisual) exige novas bases metodológicas de ensino, pois, do contrário, seu uso corre o risco de configurar meramente instrumental e pragmático.

Por essas razões, torna-se fundamental promover o diálogo entre os conhecimentos mobilizados a partir do uso de filmes e o reconhecimento de que a linguagem fílmica pode ser um meio privilegiado de (re)configurar experiências, refletir, criticamente, sobre as práticas e construir novos saberes - momento constituinte de um espaço criador de autonomia de educadores e educandos (FREIRE, 2008).

Além disso, em resposta às questões 24 e 25 , a maioria dos docentes $(77,1 \%)$ afirma que os filmes constituem um elemento motivador para o aprofundamento do conteúdo trabalhado em sala, enquanto as dificuldades envolvem, especialmente, o acesso aos vídeos (37,8\%).

Em relação à resposta majoritária dos docentes, chama a atenção um possível trato secundarizado e desfocado da linguagem cinematográfica em suas práticas pedagógicas. Um dos indícios desse trato pode ser o fato de eles centrarem o eixo das atividades e das avaliações em concepções "conteudistas" de ensino, que, via de regra, veem o material fílmico como elemento de "ilustração" e "motivação" dos alunos (NAPOLITANO, 2011 , p. 15).

Dada a maneira como os docentes empregam filme em sala (questões $11,12,13,14,15,19,21,22,23,24$ e 251, pode-se inferir que o maior contato com cinema na Graduação envolveu maior número de vídeos assistidos e debatidos, o que não significa, necessariamente, que tais experiências 
Cinema em sala de aula: reflexões a respeito do emprego de filmes na prática docente

vieram acompanhadas de uma sistemática reflexão sobre a cultura e linguagem cinematográfica, tampouco sobre a fundamental "apropriação pedagógica" dos filmes.

\section{Formação continuada e cinema}

As questões 26 e 27 diziam respeito ao possível planejamento em torno do emprego de filmes nas práticas educativas e apreendeu-se, respectivamente, que: 52,5\% afirmaram ser alvo de discussão entre os docentes com quem trabalha, enquanto é controversa a opinião sobre a existência de tal discussão por parte dos gestores, à medida que $41 \%$ responderam ocorrer, e outros $41 \%$ assinalaram não existir.

É reforçada a ideia de que o emprego do cinema se deve à ação do próprio docente, quando mencionam, nas respostas à questão 26 , que os filmes são discutidos entre os colegas.

A troca de experiências entre os docentes envolvidos com o emprego de filmes parece acontecer de modo informal, já que as respostas à questão

19427 indicam que tal prática nem sempre é recomendada por parte da gestão escolar, perdendo-se, com isso, oportunidade valiosa de formação em serviço, capaz, nesse caso, de promover melhor diálogo entre cinema e educação.

O problema da existência ou não de reflexões entre os docentes sobre o emprego de filmes em situações de aprendizagem, tanto quanto a pouca ênfase atribuída a essa prática pelos gestores pedagógicos, é forte indício de que: 1. a escola não representa um lugar de ressignificação e reconstrução da formação docente; 2. o cinema e o audiovisual representam elementos exógenos que docentes e discentes trazem para a escola (ALMEIDA, 2001 ; DUARTE, 2009).

Por seu turno, buscou-se, na formulação das questões 28 e 29, identificar possíveis experiências envolvendo a promoção do diálogo entre cinema e educação em outras situações associadas à formação continuada dos docentes pesquisados.

Na questão 28, verificou-se que 88,6\% não participaram de algum curso que abordava o uso de filmes no ensino-aprendizagem oferecido pela Secretaria Municipal de Educação de São José do Rio Preto. Isso leva pensar, 
na verdade, na ausência de promoção de formação desse tipo, por parte desse órgão público, devido ao alto índice de negativas.

Já na questão 29, a indicação é a de que $90,2 \%$ dos docentes não participaram de qualquer outro curso voltado para a abordagem do uso de filmes no ensino-aprendizagem.

Experiências relacionadas à formação continuada igualmente poderiam enriquecer a relação entre cinema e educação, entretanto as respostas às questões 28 e 29 sugerem que tais vivências não ocorreram, segundo a maioria dos docentes pesquisados.

Por que a ausência, então, da sistemática reflexão sobre educação e linguagem cinematográfica? Seria culpa dos professores? Evidentemente que não.

problema é mais complexo e parece envolver vários fatores, muitos deles elencados neste texto, como os equivocados programas educacionais adotados pelos governos brasileiros voltados à fetichização das tecnologias ou a ausência de espaços físicos e equipamentos técnicos adequados para o uso de filmes.

Mas, do ponto de vista das práticas de ensino e aprendizagem, compreende-se que a dissociação histórica entre cinema, ambientes educacionais (escolares e extraescolares) e construção de conhecimentos seja um dos graves problemas enfrentados pelos professores em seus processos formativos. E, ao que tudo indica, por equívocos dos meios educacionais. É o que afirma Rosália Duarte:

Por incrível que pareça, os meios educacionais ainda veem o audiovisual como mero complemento de atividades verdadeiramente educativas, como a leitura de textos, por exemplo, ou seja, como um recurso adicional e secundário em relação ao processo educacional propriamente dito (DUARTE, 2009, p. 18-19).

Tomar o cinema (e o audiovisual) como "recurso adicional e secundário" do processo de ensino e aprendizagem envolve uma outra questão, bastante profunda e dilemática em nossa sociedade.

Qual seria?

De acordo com a autora citada, aquela que diz respeito à falsa dicotomia entre linguagem escrita e audiovisual. Tal dicotomia, fortemente 
Cinema em sala de aula: reflexões a respeito do emprego de filmes na prática docente

assentada num modelo de formação (inicial e continuada) docente de raízes elitista e livresca, encontraria ressonância em duas visões equivocadas: a de formação dos leitores e o desinteresse pela escrita. Duarte é contundente ao problematizar tais visões:

Enquanto os livros são assumidos por autoridades e educadores como bens fundamentais para a educação das pessoas, os filmes ainda aparecem como coadjuvantes na maioria das propostas de política educacional.

$[\ldots]$

É possível que essa atitude se deva, em parte, a uma crença, mais ou menos comum, de que a relação com produtos audiovisuais (cinema e tevê, principalmente) atua de modo negativo na formação de leitores e contribui para o desinteresse por atividades pedagógicas assentadas em linguagem escrita. Mas, depois de mais de um século da criação do cinema, como podemos acreditar que existam fronteiras intransponíveis entre linguagem escrita e linguagem audiovisual? (DUARTE, 2009, p. 19).

Néstor Canclini lembra que as políticas públicas dedicadas à edu196 cação e cultura, equivocadamente, "[...] insistem em formar leitores de livros, e, à parte, espectadores de artes visuais (quase nunca de televisão) [...]", enquanto, na atualidade, "[...] a indústria está unindo as linguagens e combinando os espaços" (GARCIA CANCLINI, 2008, p. 18).

As reflexões de Rosália Duarte e Néstor Canclini remetem a algumas das dificuldades de se pensar uma interação qualitativa entre a linguagem audiovisual (o cinema) e os sujeitos do conhecimento escolar (professores e alunos), entretanto, é possível também ver a questão com outros olhos.

Desde a década de 1970, a emergência de uma cultura midiática no Brasil possibilitou a criação de novos suportes técnicos para apropriação e usos das linguagens audiovisuais (televisão e cinema). Nesse contexto, o enfoque maior recaiu sobre as gerações mais jovens que, rapidamente, foram incorporadas à "[...] cultura da imagem, do texto fragmentado, da montagem e bricolagem" (SETTON, 2004, p. 68).

Assim, pensando na formação continuada lembora isso sirva também para a formação inicial), indaga-se: é possível (e viável) mobilizar novos 
saberes através de um uso participante e criador das tecnologias em práticas educativas?

Uma das razões para apostar no papel heurístico do cinema e do audiovisual em processos formativos é a crescente popularização das câmeras, softwares e programas gratuitos de edição na internet, pois têm oportunizado um horizonte de possibilidades e procedimentos de produção de vídeos educativos a baixo custo (MOLETTA, 2009).

Nesse sentido, a mobilização criativa e participante de novos saberes - fundamentada em experiências formativas audiovisuais - poderá partir da elaboração de projetos e práticas pedagógicas que não se limitem aos usos de materiais filmográficos como recursos didáticos, mas que oportunizem aos alunos o envolvimento direto com experiências de montagem, produção e estruturação de vídeos no estilo de documentários de curta duração (BAYÃO, 2002; WAINER, 2010).

Recentemente, a internet não apenas potencializou essa incorporação da "cultura da imagem", como também oportunizou a produção e o compartilhamento de vídeos, o que leva a pensar tanto na relevância de se apostar em processos formativos voltados para o emprego consciente e critico do audiovisual, quanto na valorização de um "currículo cultural", que não reconhece fronteiras entre o conhecimento escolar e cotidiano (SETTON, 2004, p. 131-1321.

Tais experiências favoreceriam, inclusive, reflexões sobre cinema e o emprego de filmes em situações de aprendizagem, além do conjunto de disciplinas "História, Geografia e Ciências", isto é, em direção à "Língua Portuguesa e Matemática" e "Artes e Educação Física" (questão 20).

A maioria das respostas (dissertativas) expressa por conta da questão 30 confluem, justamente, para o reconhecimento da necessidade de formação mais qualificada para o emprego do cinema na educação, por parte dos próprios docentes entrevistados.

\section{Considerações finais}

A relação potencial entre o campo da educação e as Tecnologias da Informação e Comunicação é enfatizada nos estudos que, atualmente, são produzidos a respeito do ensino no Brasil. Nesse contexto, o cinema figura como 
sendo promissor, devido às inúmeras possibilidades que comporta para construção de um saber escolar dotado de predicados como: critico, autônomo, significativo, reflexivo, lúdico e dialógico.

A pesquisa ora apresentada indica que os docentes atuantes no Ensino Fundamental I ( $7^{\circ}$ a $5^{\circ}$ anos) da rede pública municipal de ensino de São José do Rio Preto (SP) percebem a possibilidade do cinema para desenvolvimento de suas práticas educativas.

No entanto, em inúmeras respostas, tais docentes igualmente revelam a falta de maior fundamentação para emprego dos filmes em sala de aula e, por isso, o uso dentro dos "limites do possível".

A explicação para essa falta de maior fundamentação envolve experiências associadas ao uso de filmes na educação básica e na formação inicial, ao que se soma a ausência de vivências dessa natureza durante a formação em serviço e outros casos de formação continuada.

Assim, com base no que marcou a sua trajetória escolar (bem ou mal), na partilha de experiências com outros colegas e naquilo que promove por conta própria (incluindo situações cotidianas, de lazer) é que o docente, normalmente, promove o emprego de filmes no processo de ensino-aprendizagem do qual faz parte.

A cultura escolar parece não incorporar, de fato, o emprego do filme nas práticas educativas, na medida em que a gestão não participa mais fortemente da apropriação pedagógica do cinema, dedicando esforços, basicamente, ao aparelhamento técnico ou ao ajuste arquitetônico lequipamentos e salas especificas, portanto) da unidade escolar para exibição de filmes.

Limites à parte, há de se reconhecer que o apreço dos docentes por cinema, o emprego que já fazem dos filmes nas aulas, somado ao aparelhamento técnico e arquitetônico para exibição de filmes existentes nas escolas indicam que experiências bem constituídas de formação continuada podem colaborar para que os filmes sejam mais bem utilizados no desenvolvimento das práticas educativas.

As experiências de formação continuada devem ser promovidas, com o intuito de favorecer o entendimento do cinema como sendo uma linguagem constituída de elementos próprios, por conseguinte, exigindo para um exitoso uso educativo: planejamento, condições de uso e avaliações que levem em conta suas especificidades. 
Tais experiências de formação continuada também podem suscitar a produção de filmes em ambientes escolares pelos próprios docentes e discentes, valendo-se assim de possibilidades geradas pelo cinema digital e a internet para construção de narrativas cinematográficas cujo processo de elaboração e conteúdos se apresentem significativos para a comunidade escolar.

Visualizar esse quadro também significa reconhecer a necessidade de promover ações em torno da alfabetização cinematográfica na formação inicial do futuro docente, por meio de esforços diversos e combinados, caso da vivência de disciplinas específicas, da produção de filmes experimentais, projetos de extensão e eventos culturais, como mostras e sessões de "cines-debate".

É possível a constituição de um processo de ensino e de aprendizagem diferenciado, se levadas adiante tais experiências, porque mais autoral, sensível e profundo, em virtude de o cinema oportunizar a mobilização e a construção de conhecimentos, com base no dialogismo entre os atores educacionais, consequentemente, a interconexão de saberes, além de permitir o trabalho com o entorno, a realidade circundante e o cotidiano no qual está inserida a escola.

\section{Nota}

1 ○ texto em questão foi elaborado com base em pesquisa desenvolvida sob os auspícios da PróReitoria de Pesquisa da UNESP, por meio do Programa 'RENOVE'.

\section{Referências}

ALMEIDA, Milton José. Imagens e sons: a nova cultura oral. São Paulo: Cortez, 2001.

Cinema - arte da memória. Campinas: Autores Associados, 2009.

ALMEIDA, Maria Elizabeth Bianconcini; VALENTE, José Armando. Integração currículo e tecnologias e a produção de narrativas digitais. Currículo sem Fronteiras, v. 12, n. 1, p. 57-82, set./dez. 2012.

ALVES-MAZZOTTI, Alda; GEWANDSZNAJDER, Fernando. O método nas ciências naturais e sociais: pesquisa quantitativa e qualitativa. São Paulo: Pioneira, 1999.

ANDRÉ, Marli; LUDKE, Menga. Estudo de caso em pesquisa e avaliação educacional. Brasília: Líber livro, 2005. 
ARAÚjO, Inácio. Cinema: o mundo em movimento. São Paulo: Scipione, 1995.

ARAÚJO FILHO, Waldemir de. Cinema e ensino de história na perspectiva de professores de história. 2007. 116 f. Dissertação (Mestrado em Educação) - Programa de Pós-Graduação em Educação, Pontifícia Universidade Católica do Rio de Janeiro, Rio de Janeiro, 2007

AZEVEDO, Abílio. Territorialidade e Plano Diretor em São José do Rio Preto. 2004. 275f. Dissertação (Mestrado em Geografia) - Programa de Pós-Graduação em Geografia, Universidade Estadual Paulista de Rio Claro, Rio Claro, 2004.

BABBIE, Earl. Métodos de pesquisa de Survey. Tradução Guilherme Cezarino. 3. ed. Belo Horizonte: Ed. UFMG, 2005.

BARRETO, Raquel Goulart. Formação de professores, tecnologias e linguagens: mapeando velhos e novos (des)encontros. São Paulo: Loyola, 2002.

BAYÃO, Luiz Gustavo. Escrevendo curtas: uma introdução à linguagem cinematográfica do curta-metragem. Niterói: Nitpress, 2002.

BELLONI, Maria Luiza; BÉVORT, Evelyne. Midia-educação: conceitos, história e perspectivas.

Educação \& Sociedade, Campinas, v. 30, n. 1, p. $1081-1$ 102, set./dez. 2009.

BENTES, Ivana. Ecos do cinema - de Lumiére ao digital. Rio de Janeiro: Editora da UFRJ, 2007.

BITTENCOURT, Circe Maria Fernandes. Ensino de história: fundamentos e métodos. 4. ed. São Paulo: Cortez, 2011.

CABRERA, Julio. O cinema pensa - uma introdução à filosofia através dos filmes. Rio de Janeiro: Rocco, 2006.

CARVAlHO, Elma Julia Gonçalves de. Cinema, história e educação. Teoria e Prática da Educação, Maringá, v. 3, n. 5, p. 121-131, set. 1998.

CARVALHO, Joelson Gonçalves de (Org.). Dimensões regionais e urbanas do desenvolvimento socioeconômico em São José do Rio Preto. São José do Rio Preto: Microlins do Brasil, 2007.

CATELI, Rosana Elisa. Dos "naturais" ao documentário: o cinema educativo e a educação do cinema, entre os anos 1920 e 1930. 2007. 244 f. Tese (Doutorado em Multimeios) - Programa de Pós-Graduação em Multimeios, Universidade Estadual de Campinas, Campinas, 2007. 
CHARNEY, Leo; SCHWARTZ, Vanessa (Org.). O cinema e a invenção da vida moderna. Tradução Regina Thompson. São Paulo, Cosac Naify, 2001.

COLl, César; MONEREO, Carles (Org.). Psicologia da educação virtual: aprender e ensinar com as tecnologias da informação e da comunicação. Tradução Naila Freitas. Porto Alegre: Artmed, 2010.

CRARY, Jonathan. Techniques of the observer: on vision and modernity in the modernity in the nineteenth century. Cambridge/Massachussets: MIT Press, 1995.

DE LUCA, Luiz Gonzaga. A hora do cinema digital: democratização e globalização do audiovisual. São Paulo: Imprensa Oficial do Estado de São Paulo, 2009.

DENZIN, Norman; LINCOLN, Yvonna. Planejamento da pesquisa qualitativa: teorias e abordagens. Porto Alegre: Artmed, 2006.

DUARTE, Rosália. Cinema e educação: refletindo sobre cinema e educação. 3. ed. Belo Horizonte: Autêntica, 2009.

DUARTE, Rosália; LEITE, Camila Rodrigues; MIGLIORA, Rita. Produção de sentido e construção de valores na experiência com o cinema In: SETTON, Maria das Graças (Org.). A cultura da mídia na escola: ensaios sobre cinema e educação. São Paulo: Annablume, 2004.

FARIA, Gentil. A educação primária em Rio Preto: o processo de municipalização do ensino. São José do Rio Preto: THS/Arantes, 2008.

FISCHER, Rosa Maria. Docência, cinema e televisão: questões sobre formação ética e estética. Revista Brasileira de Educação, Rio de Janeiro, v. 14, n. 40, p. 93-102, jan./abr. 2009.

FONSECA, Selva Guimarães. Caminhos da história ensinada. Campinas: Papirus, 1993.

Didática e prática de ensino de história. 8. ed. Campinas: Papirus, 2009.

FREIRE, Paulo. Pedagogia da autonomia: saberes necessários à prática docente. São Paulo: Paz e Terra, 2008.

GAMBOA, Silvio Sanchez (Org). Pesquisa educacional: quantidade-qualidade. São Paulo: Cortez, 1997.

GARCIA CANCLINI, Néstor. Leitores, espectadores e internautas. Tradução Ana Golberger. São Paulo: Iluminuras, 2008. 
JOLY, Martine. Introdução à análise da imagem. 14. ed. Tradução Marina Appenzeller. Campinas: Papirus, 2012.

KONRATH, Maria Lúcia; CARNEIRO, Maria Lúcia; CARVALHO, Marie Jane; TAROUCO, Liane Margarida. Explorando estratégias pedagógicas através de "Nós no mundo." Novas Tecnologias na Educação, Porto Alegre, v. 4, n. 2, p. 1-9, dez. 2006.

MESQUITA, Claudia; LINS, Consuelo. Filmar o real: sobre o documentário brasileiro contemporâneo. Rio de Janeiro: Zahar, 2008.

MINAYO, Maria Cecília; DESLANDES, Suely Ferreira \& GOMES, Romeu (Org.). Pesquisa social: teoria, método e criatividade. Petrópolis: Vozes, 2000.

MOLETTA, Alex. Criação de curta metragem em vídeo digital: uma proposta para produções de baixo custo. São Paulo: Summus, 2009.

MONTEIRO, Ana Nicolaça. O cinema educativo como invocação pedagógica na escola primária paulista (1933-1944). 2006. 169f. Dissertação (Mestrado em Educação) Programa de Pós-Graduação em Educação, Universidade de São Paulo, São Paulo, 2006.

NAPOLITANO, Marcos. Como usar o cinema na sala de aula. 5. ed. São Paulo: Contexto, 2011.

NASCIMENTO, Vera Lúcia do. Cinema e ensino de história: em busca de um final feliz. Urutágua, Maringá, v. 1, n. 16, p. 11-19, ago./nov. 2008.

NOVAES, Adauto (Org.). O olhar. São Paulo: Companhia da Letras, 1997.

PERINELLI NETO, Humberto. Tempo, espaço e cinema: prática de ensino de história e geografia. In: GRANVILLE, Maria Antônia (Org.). Currículos, sistemas de avaliação e práticas educativas: da escola básica à universidade. Campinas: Papirus, 2011.

PIMENTA, Selma Garrido (Org.). Saberes pedagógicos e atividade docente. São Paulo: Cortez, 1999.

PONTUSCHKA, Nídia; PAGANELLI, Tomoko; CACETE, Núria (Org.). A linguagem cinematográfica no ensino de geografia. In: Para ensinar e aprender geografia. São Paulo: Cortez, 2009.

POURRIOUL, Ollivier. Cinéfilo - as mais belas questões de filosofia no cinema. Tradução André Telles. Rio de Janeiro: Zahar, 2009. 
SALIBA, Maria Eneida Fachini. Cinema contra cinema: o cinema educativo de Canuto Mendes (1922-193 1). São Paulo: Annablume/Fundação de Amparo a Pesquisa do Estado de São Paulo, 2003.

SETTON, Maria da Graça (Org.). A cultura da mídia na escola - ensaios sobre cinema e educação. São Paulo: Annablume, 2004.

SOARES, Marisa. Cinema e história ou cinema na escola. Primeiros Escritos, Niterói, v. 1, n. 1, p. 237-250, jul./ago. 1994.

SPSS. Statistical Package for the Social Sciences. IBM SPSS statistics for windows v. 20.0. Chicago: SPSS Inc., 2011.

TARDIF, Maurice. Saberes docentes e formação profissional. Tradução Francisco Pereira. Petrópolis: Vozes, 2002.

TRIVINÕS, Augusto. Introdução à pesquisa em ciências sociais - a pesquisa qualitativa em educação. São Paulo: Atlas, 1992.

VARGAS, Ariel; ROCHA, Heloísa \& FREIRE, Fernanda. Promídia: produção de vídeos digitais no contexto educacional. Novas Tecnologias na Educação, Porto Alegre, v. 5, n. 2, p. 145 151, dez. 2007.

XAVIER, Ismail. Cinema: revelação e engano. In: NOVAES, Adauto (Org.). O olhar. São Paulo: Companhia das Letras, 2002.

WAINER, Julio. Idéia, imagens e sons: caminhos para a estruturação de um documentário. 2010. 122f. Dissertação (Mestrado em Comunicação) - Programa de Pós-Graduação em Comunicação, Pontifícia Universidade Católica de São Paulo, São Paulo, 2010.

Prof. Dr. Humberto Perinelli Neto Universidade Estadual Paulista | São José do Rio Preto Departamento de Educação Grupo de Pesquisa Centro Interdisciplinar de Estudos Regionais | UNESP Formação Docente e Práticas Educativas | UNESP E-mail | perinellineto@yahoo.com.br 
Prof. Dr. Rodrigo Ribeiro Paziani Universidade Estadual do Oeste do Paraná | Unioeste | Campus de Marechal Candido Rondon

Centro de Ciências Humanas, Educação e Letras (CCHEL) Programa de Pós-Graduação em História (Mestrado) |Unioeste |Marechal Candido Rondon

Grupo de Pesquisa Centro Interdisciplinar de Estudos Regionais | UNESP Formação Docente e Práticas Educativas | UNESP História Social do Trabalho e da Cidade | Unioeste | Marechal Candido Rondon E-mail | rpaziani@yahoo.com.br Recebido 7 jul. 2015 Aceito 19 ago. 2015 